\title{
Clinical and molecular advances in autosomal dominant cerebellar ataxias: from genotype to phenotype and physiopathology
}

\author{
Giovanni Stevanin ${ }^{1}$, Alexandra Dürr ${ }^{1,2,3}$ and Alexis Brice ${ }^{1,2,3}$ \\ ${ }^{1}$ INSERM U289, ${ }^{2}$ Fédération de Neurologie and ${ }^{3}$ Consultation de Génétique Médicale, Groupe Hospitalier \\ Pitié-Sal pêtrière, Paris, France
}

\begin{abstract}
Major advances have been made in the understanding of autosomal dominant cerebellar ataxias since genetic markers came into use in the 1980s. The subsequent mapping of nine genes, six of which have been identified, involved in this clinically diverse group of disorders highlighted their great genetic heterogeneity. Evidence is now accumulating that, except for SCA8, the same molecular and physiopathological processes underlie these diseases and other neurodegenerative disorders sharing the same mutational basis, the expansion of a (CAG)n-polyglutamine coding sequence. The clinical overlap among the different genetic entities makes prediction of the molecular origin impossible in a single patient so that molecular characterisation is necessary. However, extended clinical and neuropathological comparisons have shown that each genetic entity has a characteristic constellation of signs and symptoms that are related to CAG repeat size and disease duration. The combined genetic and clinical information form the basis of a new classification that will aid better understanding of disease evolution, assure follow up and permit genetic counselling by the clinician. European Journal of Human Genetics (2000) 8, 4-18.
\end{abstract}

Keywords: autosomal dominant cerebellar ataxia; polyglutamine expansion; spinocerebellar ataxias; anticipation; genetic heterogeneity; clinical and genetic correlations

\section{Introduction}

The hereditary ataxias comprise a wide spectrum of diseases with different clinical and neuropathological profiles. Genetic advances during the last decade have shown that they constitute the majority of neurodegenerative disorders caused by trinucleotide repeat expansions, including Friedreich's ataxia (FA) and six forms of autosomal dominant cerebellar ataxias (ADCA).

The clinical and pathological heterogeneity that is found even among affected members of the same family makes accurate clinical diagnosis difficult. The first attempts to classify these disorders were unsatisfactory for several reasons. They were based on a small number of anatomopatho-

Correspondence: Professor A Brice, INSERM U289, Hôpital de la Salpêtrière, 47 Bd de l'Hôpital, 75651 Paris, Cedex 13, France. Tel: +33142 1621 82; Fax: + 331442436 58; E-mail: brice@ccr.jussieu.fr Received 7 June 1999; revised 1 September 1999; accepted 3 September 1999 logical observations that were not hel pful in clinical practice and did not take into account disease duration or mode of inheritance. ${ }^{1-3}$ Furthermore, patients from the same family often fell into different pathological categories, whereas patients with different aetiologies presented with similar disorders. These difficulties led Harding to propose a classification, now widely accepted, based solely on the mode of inheritance and on clinical criteria. ${ }^{4-6}$

FA, the most frequent form of ataxia, is a recessive disorder $^{7,8}$ caused by a $(G A A)_{n}$ expansion in the first intron of the $X 25$ gene on chromosome $9 .^{9}$

ADCA constitute a more clinical and molecular heterogeneous group of disorders. The recent demonstration that a coding CAG repeat expansion is common to five of the identified ADCA genes, is providing new insights into their physiopathology and partly explain their clinical heterogeneity. A new classification is now emerging from the molecular and clinical data (Table1). 
Table 1 Clinical $^{6}$ and molecular classification of ADCA

\begin{tabular}{|c|c|c|c|c|c|c|}
\hline \multirow[b]{2}{*}{ ADCA type } & \multirow{2}{*}{$\begin{array}{l}\text { Signs associated with } \\
\text { cerebellar ataxia }\end{array}$} & \multirow[b]{2}{*}{ Gene } & \multirow[b]{2}{*}{ Locus } & \multirow[b]{2}{*}{ Frequency } & \multicolumn{2}{|c|}{ Repeat number range } \\
\hline & & & & & Normal & Pathological \\
\hline \multirow{4}{*}{ I } & $\begin{array}{l} \pm \text { Ophthalmoplegia } \\
\pm \text { optic atrophy }\end{array}$ & SCA1 & $6 p 23$ & $5-40 \%$ & $6-44$ & $39-83$ \\
\hline & \pm dementia & $\mathrm{SCA} 2$ & $12 q 24.1$ & $10-40 \%$ & $13-33$ & $32-77$ \\
\hline & $\begin{array}{l} \pm \text { extrapyramidal signs } \\
\pm \text { amyotrophy }\end{array}$ & SCA3/MJD & $14 q 32.1$ & $11-84 \%$ & $12-40$ & 54-89 \\
\hline & & $\begin{array}{l}\text { SCA4 } \\
\text { SCA12 } \\
\text { other }\end{array}$ & $\begin{array}{l}16 q 22.1 \\
5 \\
?\end{array}$ & $\begin{array}{l}1 \text { family } \\
1 \text { family } \\
?\end{array}$ & $7-28$ & $>65$ \\
\hline II & $\begin{array}{l}\text { Progressive macular } \\
\text { dystrophy } \\
\pm \text { ophthalmoplegia } \\
\pm \text { dementia } \\
\pm \text { extrapyramidal signs }\end{array}$ & $\begin{array}{l}\text { SCA7 } \\
\text { other }\end{array}$ & $\begin{array}{l}\text { 3p12-13 } \\
?\end{array}$ & $\begin{array}{l}5-8 \% \\
1 \text { family }\end{array}$ & $4-35$ & $37-306$ \\
\hline \multirow[t]{2}{*}{ III } & Pure cerebellar syndrome & $\begin{array}{l}\text { SCA5 } \\
\text { SCA6 } \\
\text { SCA8 } \\
\text { SCA11 }\end{array}$ & $\begin{array}{l}\text { 11cen } \\
\text { 19p13.1 } \\
13 q 21 \\
15 q 14-21.3\end{array}$ & $\begin{array}{l}2 \text { families } \\
1-16 \% \\
-5 \% \\
1 \text { family }\end{array}$ & $\begin{array}{l}4-18 \\
16-92\end{array}$ & $\begin{array}{l}20 / 21-33 \\
107-250\end{array}$ \\
\hline & Ataxia and epilepsy & $\begin{array}{l}\text { SCA10 } \\
\text { TBP }\end{array}$ & $\begin{array}{l}22 q 13 \\
6 q 27\end{array}$ & $\begin{array}{l}2 \text { families } \\
1 \text { case }\end{array}$ & $25-42$ & 63 \\
\hline
\end{tabular}

\section{Towards a unifying clinical and molecular classification of ADCA}

ADCA are characterised by variable degrees of cerebellar and brainstem degeneration or dysfunction. Neuronal loss variably affects the pons, the olives, the basal ganglia, the cerebellum and its afferences and efferences. Onset is generally during the third of fourth decade but can also occur in childhood or in the elderly. Patients usually present with progressive cerebellar ataxia and associated neurological signs that define three distinct phenotypes according to Harding's clinical classification. ${ }^{6}$

ADCA typel is the most common subtype and variably combines cerebellar ataxia and dysarthria, ophthalmoplegia, pyramidal and extrapyramidal signs, deep sensory loss, amyotrophy and dementia. However, several other signs and symptoms can be associated as well, ie slow eye movements, sphincter disturbances, axonal neuropathy, fasciculations or swallowing difficulties. The genes for four different forms of ADCA typel have been localised: spinocerebellar ataxia (SCA) 1 on chromosome $6 p,{ }^{10}$ SCA2 on $12 q,{ }^{11}$ SCA3 or MachadoJoseph disease (MJD) on $14 q^{12,13}$ and SCA4 on $16 q^{14}$ The association of progressive macular degeneration with cerebellar ataxia is characteristic of ADCA typell, the gene for which has been mapped to the SCA7 locus on chromosome 3p. ${ }^{15-17}$ Finally, ADCA typelll denotes a 'pure', generally late onset, cerebellar syndrome. Two loci, designated SCA5 and SCA11 have been mapped to chromosomes 11 cen ${ }^{18}$ and $15 q,{ }^{19}$ respectively, and a CACNA1A gene mutation, denoted SCA6, is also responsible for a pure cerebellar syndrome. ${ }^{20}$ Furthermore, a locus (SCA 10) has been mapped to chromosome22q13 in two Mexican pedigrees presenting with ataxia and seizures. ${ }^{21,22}$
An polyglutamine-coding (CAG) repeat expansion has been identified as responsible for the disease in five of these genes: SCA $1,{ }^{23} \mathrm{SCA} 2,^{24-26} \mathrm{SCA} 3 / \mathrm{MJD},{ }^{27-29} \mathrm{SCA}^{20}$ and SCA 7. ${ }^{30-32}$ These disorders share common properties, with few exceptions, with other polyglutamine diseases such as Huntington's disease (HD), spinal bulbar and muscular atrophy (Kennedy's disease), and dentatorubral and pallidoluysian atrophy: ${ }^{33}$

a) onset is mostly in adulthood, but some juvenile cases are observed, especially when transmitted by affected fathers;

b) the disease course is progressive, unremitting and usually fatal after 10-30 years of evolution;

c) the clinical symptoms appear above a threshold number of CAG repeats ranging from 20 in SCA6 to 54 in SCA3/MJD;

d) there is a strong negative correlation between the number of CAG repeats and age at onset;

e) the repeat sequence is unstable and its increase in size during transmission results in genetic anticipation, except for SCA6;

f) the gene is expressed ubiquitously;

g) the pathological protein accumulates in ubiquitinated neuronal intranuclear inclusions in several affected but also in non-affected brain structures.

Other loci responsible for the different subgroups of ADCA will probably be discovered. A CAG repeat sequence of more than 40 units has been found by the Repeat Expansion 
Detection method in several patients that are not linked to known loci. ${ }^{34}$ There is, however, no evidence of another specific protein with polyglutamine expansions (encoded by codons CAA and CAG) in non-SCA1-7 families suggesting that the repeat might be smaller than the detection threshold or different in nature. ${ }^{35}$ Interestingly, a CTG triplet repeat expansion in a non-coding region of the SCA 8 gene has been implicated in a large family. ${ }^{36}$ More recently, CAG expansions in the tata-binding protein gene (TBP) and in the $5^{\prime}$ region of a regulatory subunit of protein phosphatase $2 \mathrm{~A}$ (SCA12) have been implicated in a sporadic case and in a single family with ataxia, respectively. ${ }^{177,178}$

\section{Frequency and origin of the mutations}

The prevalence of ADCA is not precisely known but it appears to be less than $10 / 100000 .^{37,38}$ Most reports concern populations with probable founder effects, such as SCA2 in the province of Holguin in Cuba $(4 / 10000)^{39}$ or SCA3/MJD in the Azores in Portugal (1/4000). ${ }^{40}$

The relative frequencies of the different CAG repeat expansions have been determined by molecular typing in several populations. ${ }^{41-54}$ However, most of the large series do not clearly indicate the ethnic and/or geographical origin of the families. Although in most countries SCA3/MJD is the major locus, the relative frequencies of SCAs vary widely according to the geographical origin. SCA3/MJD represents $80 \%$ of the families in Portugal and is also frequent in France (30\%), Germany (40\%) and Japan (39\%) but has not been detected so far in Italy. ${ }^{55}$ SCA 6 is frequent in Japan (30\%) and Germany (13\%) but quite rare in neighbouring France ${ }^{53}$ and Spain. ${ }^{56}$

These differences are probably accounted for by regional founder effects. Linkage disequilibrium, which reflects the existence of a single or a major founder effect, has been detected with flanking markers at the SCA1 locus in Japan, ${ }^{57}$ SCA2 in Northern Europe, ${ }^{58}$ SCA3/MJD in France, Portugal and Japan ${ }^{59-63}$ and SCA7 in Korea, North Africa, Continental Europe and Anglo-Saxon countries. ${ }^{64}$ A strong linkage disequilibrium is also detected in German SCA6 pedigrees which probably descend from a single founder, since the repeat is not unstable in this disease. ${ }^{65}$ Conversely, intragenic polymorphisms in the SCA3/MJD gene showed that, in Portugal, where this locus is responsible for almost all ADCAs, several different founders existed. ${ }^{63}$ These studies demonstrate that the SCA3/MJD mutation was not transmitted by Portuguese sailors or travellers to the rest of the world, as previously hypothesised, ${ }^{40,66,67}$ since haplotype observed in black African and Jewish Yemenite SCA3 patients has not been found in Portuguese patients. ${ }^{63}$

Genetic studies have not only reveal ed the existence of founder effects but they have also provided insight into the mechanism of the mutation. De novo SCA mutations are probably rare, except in SCA7 where several cases have been observed or inferred from paternal transmissions. ${ }^{68}$ These neomutations resulted from the expansion of large normal alleles, often designated as intermediate alleles (IA), that contain from 28 to 35 CAG units. It is interesting to note that de novo cases of ADCA have only been reported in SCA7, which presents the greatest degree of instability during transmission and the greatest anticipation among the polyglutamine repeat diseases. These observations suggest, as has been confirmed in Huntington's disease (HD) ${ }^{69}$ and SCA3/ $M J D,{ }^{70}$ that the degree of instability increases with the size of the normal alleles even before they reach the pathological range. If this observation is extended to all SCAs, it can be expected that in a given population de novo mutations at a given locus occur once or recurrently on IA. Therefore the relative frequency of SCAs should correlate with the frequency of IA in a given population. A recent study on Japanese, French and American families provided results in agreement with this hypothesis. ${ }^{50}$ For example, the proportion of IA at the DRPLA locus in Japanese (24\%) and Caucasians (10\%) reflects the relative disease frequency of $20 \%$ and less than $1 \%$, respectively, in these populations. More evidence supporting the idea that IA represent a reservoir for de novo mutations comes from the study of a polymorphism within the MJD1 gene. The haplotype segregating in all French SCA3/MJD families is present on only $25 \%$ of normal alleles but in all large normal alleles over 33 repeats. ${ }^{63}$

\section{Distribution of normal and expanded alleles}

Normal alleles carry a variable number of CAG repeats but the degree of polymorphism varies according to the locus. Normal SCA1, SCA3 and SCA6 alleles are very polymorphic, with heterozygosity rates of approximately $80 \%$, whereas normal SCA 2 and SCA 7 heterozygotes represents only 24 and $35 \%$, respectively. This is due to the high frequency, close to $80 \%$, of alleles with 22 and 10 CAG repeats at the SCA2 and SCA7 locus, respectively. . $^{30,71}$

The size distribution of expanded alleles is even greater, except in SCA6, but a specific pathological threshold is observed for each locus, ranging from 20 repeats in SCA6 to 54 in SCA3/MJD. ${ }^{72,73}$ Only few expansions exceed 100 repeat units and are associated with infantile cases in $\mathrm{SCA} 2^{74}$ and SCA7. ${ }^{75-78}$ Usually, normal and expanded alleles carry uninterrupted CAG repeats and there is no overlap between the normal and pathological range. There are, however, two exceptions, SCA1 and SCA2, in which most of the normal alleles are interrupted by 1 to 3 CAT or CAA respectively, and can attain the size of small pathological expansions, albeit rarely. ${ }^{71,79,80}$ It is believed that the interruptions stabilise these alleles which are transmitted without modification, even when they reach the size of pathological expansions. In these cases, sequencing distinguishes the interrupted large normal alleles from the uninterrupted small pathological expansions. These rare situations may be encountered during molecular testing. 
The size range of the untranslated CTG repeat at the SCA8 locus is wider than in the polyglutamine diseases. ${ }^{36}$ Normal alleles commonly carry from 16 to 37 repeats but chromosomes with up to 92 repeats have been detected in controls. In ataxic patients, pathological chromosomes have from 107 to 127 CTG repeats.

\section{Instability and anticipation}

Instability is a major characteristic of mutations caused by trinucleotide repeat expansions and is observed at both the somatic and the gonadal levels. Normal alleles are usually transmitted to progeny without modification. Most expansions (except SCA6), however, are unstable during transmission, with a tendency to increase in successive generations. At the SCA1, SCA2 and SCA7 loci, there is a tendency for greater instability during paternal than during maternal transmissions (Table2), particularly for the largest expansions ( > 20 CAG units). The result of instability is an increase in the mean size of the expansion over successive generations. However, the mean increase per generation varies greatly depending on the locus, ranging from approximately +0.7 for SCA3/MJD to +12 for SCA $7 .{ }^{81}$ Except in SCA7, ${ }^{75}$ there is no correlation with the size of the repeat sequence, suggesting that flanking sequences may account for interloci differences in instability.

Instability during transmission results from gonadal mosaicism which can be easily detected in the sperm of patients. Analysis of whole or single sperm reveals much greater mosaicism of the expansion at the SCA7 locus than the SCA3/MJD locus, which is in accordance to the differences observed during transmissions. ${ }^{28,75}$ Mosaicism is also detected in somatic tissues, including the central nervous system, but is always much less pronounced than gonadal mosai cism. ${ }^{82-86}$

CAG repeat instability is thought to result from slippage during DNA replication or from the formation of stable hairpin structures. In the latter case, this will result in large expansions or contractions depending on their location on the leading or lagging strand, respectively. ${ }^{87-89}$ Genetic and epigenetic factors, such as the position and orientation with

Table 2 Comparison of CAG repeat instability during transmission to progeny at loci SCA1, SCA3/MJD (G Stevanin, A Dürr, A Brice, unpublished data, 1998), SCA2 ${ }^{26,71}$, SCA $^{81}$, DRPLA $^{167,168}$, SBM A $^{169-171}$ and HD ${ }^{172,173}$

\begin{tabular}{lll}
\hline & \multicolumn{2}{l}{ Gender of the transmitting parent } \\
& Male & Female \\
\hline SCA1 & $+2.0(-2$ to $+8, n=16)$ & $+0.2(-1$ to $+1, n=5)$ \\
SCA2 & $+3.5(-8$ to $+17, n=33)$ & $+1.7(-4$ to $+8, n=23)$ \\
SCA3/MJD & $+0.9(-3$ to $+5, n=26)$ & $+0.6(-8$ to $+3, n=34)$ \\
SCA7 & $+12.1(0$ to $+85, n=34)$ & $+4.8(-6$ to $+18, n=34)$ \\
DRPLA & $+7.0(0$ to $+28, n=33)$ & $+0.3(-4$ to $+4, n=9)$ \\
SBMA & $+1.8(-2$ to $+5, n=11)$ & $+0.2(-4$ to $+2, n=20)$ \\
HD & $+6.1(-4$ to $+74, n=156)$ & $+0.6(-4$ to $+16, n=160)$ \\
\hline
\end{tabular}

regard to the origin of replication, can modify repeat instability in Escherichia coli ${ }^{88}$ and Saccharomices cerevisiae. ${ }^{90-92}$ Instability is also influenced by the size of the repeat required to form stable structures as demonstrated in HD and SCA $7 .^{75,93}$ In SCA3/MJD, the analysis of polymorphisms located close to the CAG repeat showed that they act both in trans and in cis $^{70,94}$ Sex-dependent instability is thought to be due to the difference between spermatogenesis and ovogenesis. The latter stops early during embryogenesis, whereas the former continues throughout life, resulting in a much larger number of mitoses. This may explain why the CAG repeat in $\mathrm{HD}$ is more unstable when the age at conception increases. ${ }^{95}$ The human mismatch repair 2 protein (MSH2), which binds specifically to CAG repeats, might also interfere with repeat stability. ${ }^{96}$ It is interesting to note that triplet repeats are located within regions with a high GC content. ${ }^{97}$

Instability at the SCA8 locus, caused by an untranslated CTG repeat, is even more marked since parent-child differences in the number of repeats, ranging from -86 to +600 , have been observed. ${ }^{36}$ Furthermore, a maternal bias in this disease results in greater instability during mother-child than father-child transmissions. These observations are reminiscent of the group of diseases, including myotonic dystrophy, caused by untranslated trinucleotide repeats. ${ }^{33,98}$

Gonadal instability is the molecular basis of a major feature of ADCAs - the phenomenon of anticipation, ie the earlier onset and/or more severe course of the disease in successive generations. Due to the increase in size of the expansion from generation to generation and to the negative correlation between expansion size and the age at onset (Figure1), the mean age at onset of ADCAs decreases with successive generations. The greatest anticipation is therefore found in SCA7 families in which the expansion is very unstable. However, anticipation is usually overestimated because of observation biases. We have shown that the expected anticipation in SCA2, determined from the CAG expansion size/age at onset correlation curve was 12 years, whereas it was 20 years when calculated from the ages at onset in parent-child pairs. $^{71}$ Likewise, in SCA3, the expected and observed anticipations were 5 and 12 years, respectively. ${ }^{52}$ In SCA7, however, expected and observed anticipations were similar. ${ }^{75}$ Although anticipation was reported to be greater in paternal than in maternal SCA 7 transmissions, ${ }^{99,100}$ this has not been confirmed in recent reports, ${ }^{31,75,76,78}$ although all juvenile cases are transmitted by affected fathers. Surprisingly, anticipation has also been reported in SCA6 families in which no instability occurs ${ }^{44,54,101}$ This also probably results from an observation bias. ${ }^{53}$ Observation of slight anticipation is therefore not sufficient to conclude that an unstable mutation is involved in a disease.

In the absence of meiotic distortion, anticipation should lead to extinction of the disorder in carrier families after a variable number of generations because the disease is not transmitted by infantile or juvenile patients. If the disease 

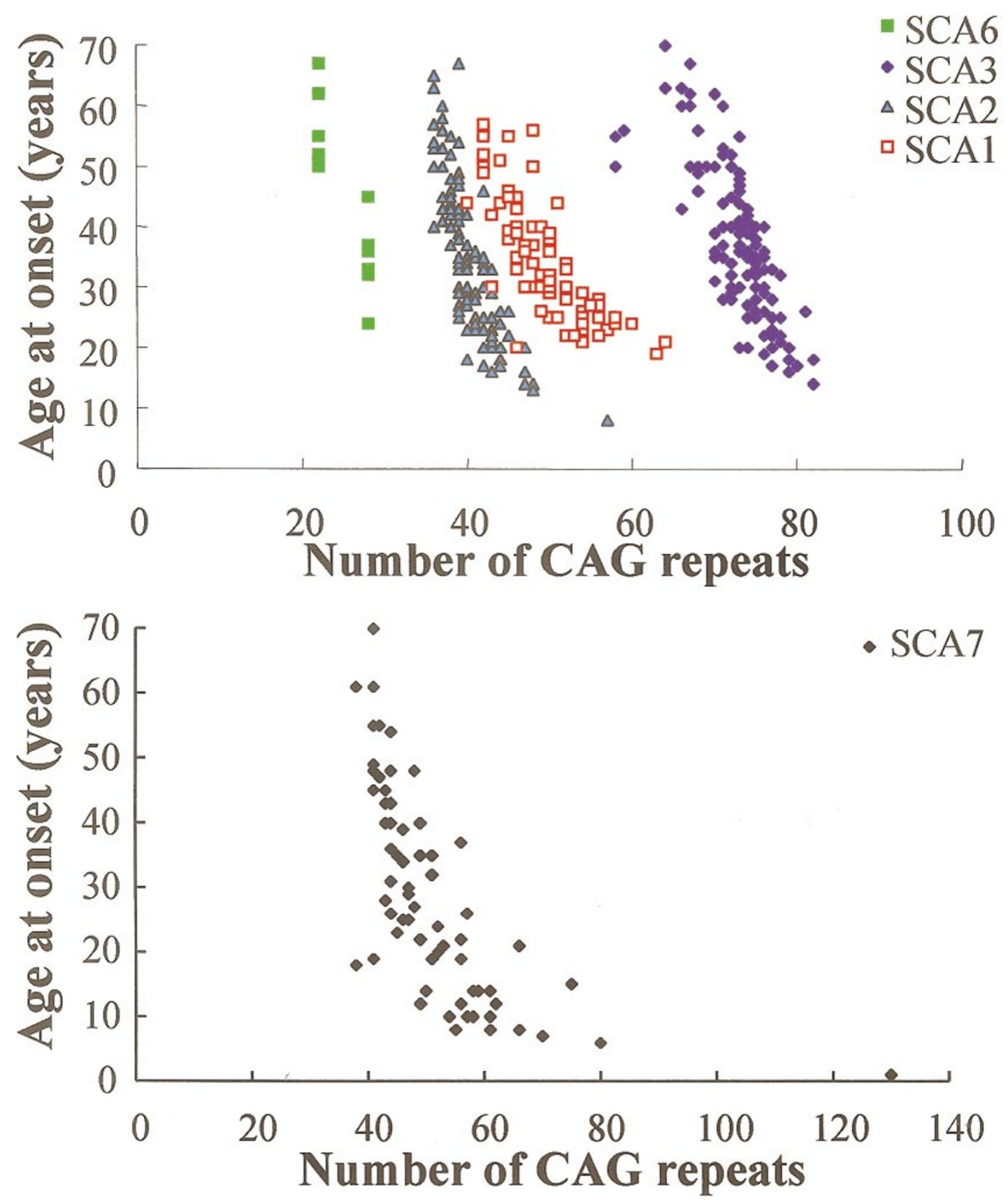

Figure 1 Age at onset/CAG repeat number correlation curves in spinocerebellar ataxias. ${ }^{52,53,71,75,174,175}$

remains in equilibrium, de novo mutations must occur to replace the non-transmitted pathological alleles. This seems to be the case in SCA7 in which there is marked anticipation, frequent de novo mutations and IA in unaffected branches of the SCA7 pedigrees. ${ }^{68}$ On the contrary, the number of de novo mutations is probably very low in SCA6 in which the repeat sequence is stable. The strong linkage disequilibrium in German SCA6 kindreds is consistent with this hypothesis. ${ }^{65}$

\section{Phenotypes and neuropathological features according to the locus Clinical presentation in patients}

The phenotypes of large series of genetically homogeneous patients has become possible through molecular screening. The major clinical features for SCA1, SCA2, SCA3/MJD, SCA 6 and SCA 7 patients are given in Table3. Age at onset varies widely within and among groups. There is a tendency for the 
Table 3 Frequency of neurological signs associated with SCA mutations ${ }^{52,53,71,75,174,175}$

\begin{tabular}{|c|c|c|c|c|c|}
\hline & SCA1 & SCA2 & SCA3/MJD & SCA6 & SCA7 \\
\hline Mean age at onset (years) & 34 & 35 & 38 & 45 & 30 \\
\hline Onset after 55 years & - & - & \pm & + & - \\
\hline Cerebellar syndrome & $+H$ & $+H$ & ++ & $+H$ & ++ \\
\hline Dysarthria & $+H$ & $+H$ & ++ & + & ++ \\
\hline Babinski sign & + & + & + & 0 & ++ \\
\hline Brisk reflexes & + & + & ++ & + & ++ \\
\hline Diminished or abolished reflexes & + & ++ & ++ & + & 0 \\
\hline Spasticity in lower limbs & + & \pm & ++ & \pm & + \\
\hline Amyotrophy & + & + & ++ & - & + \\
\hline Extrapyramidal syndrome/dystonia & \pm & \pm & + & 0 & + \\
\hline Myoclonus & - & ++ & \pm & - & \\
\hline Nystagmus & + & + & $+1+$ & ++ & + \\
\hline Ophthalmoplegia & + & + & ++ & 0 & + \\
\hline Decreased saccade velocity & + & ++ & + & 0 & $+1+$ \\
\hline Decreased visual acuity & 0 & 0 & 0 & 0 & $+H$ \\
\hline Bulging eyes & + & + & + & 0 & + \\
\hline Myokymia & + & ++ & + & 0 & + \\
\hline Dysphagia & ++ & ++ & ++ & ++ & + \\
\hline Sphincter disturbances & + & ++ & ++ & ++ & + \\
\hline Dementia & + & + & + & 0 & + \\
\hline Tremor & - & + & \pm & \pm & + \\
\hline Axonal neuropathy & + & $+H$ & ++ & 0 & + \\
\hline Decreased hearing acuity & 0 & 0 & 0 & 0 & + \\
\hline
\end{tabular}

mean age at onset to be earlier in SCA7 and later in SCA6, compared with the other forms of ADCA. The only sign that is specific for a single locus is decreased visual acuity leading to blindness due to progressive macular dystrophy in most SCA7 patients. No other clinical sign is specifically associated with a given genotype. However, group differences in the frequency of several signs, and their characteristic combination observed in more than one family member, can be suggestive of the genetic subtype in some cases.

An early decrease in saccade velocity and reduced tendon reflexes without extrapyramidal signs is suggestive of SCA2. ${ }^{45,71,102,103}$ SCA3/MJD and SCA6 patients present frequently with cerebellar oculomotor signs such as saccadic smooth pursuit, gaze-evoked nystagmus and diplopia. Extrapyramidal signs, myokimia and bulging eyes have been reported to characterise Machado-Joseph disease ${ }^{104}$ but are not frequent in non-Portuguese Western European SCA3/MJD patients and might, therefore, be related to ethnic background. ${ }^{13,29,52,105}$ SCA3/MJD patients also frequently have ophthalmoplegia or amyotrophy. ${ }^{52,60,105-109}$ SCA6 patients, however, usual ly have later onset, sl ower disease progression and few neurological signs in addition to cerebellar ataxia, at least during the first decade, ${ }^{53}$ a profile that closely resembles that of SCA5 patients. ${ }^{18,110}$ Episodic ataxia has been described as the presenting sign in some SCA 6 patients. ${ }^{72}$ The clinical signs associated with the SCA1 mutation are in general broader and homogeneous, and the patients have usually a pyramidal syndrome, often with hyperreflexia. ${ }^{111}$

Paraclinical investigations can also help to identify group differences. Schöls et $\mathrm{al}^{45}$ have shown that increased conduction times in the central ( $>10 \mathrm{~ms}$ ) and peripheral ( $>18 \mathrm{~ms}$ ) nervous system are distinctive of the SCA1 phenotype.
Recording of ocular movements might also be useful, but there is some overlap of phenotypes. ${ }^{112}$ Hypermetria is frequent in SCA1, slowing of saccades in SCA2 and SCA7, gaze-evoked nystagmus and a tendency to hypometria in SCA3/MJD. Gaze-evoked nystagmus is also seen in SCA6. Cerebral MRI of SCA6 patients show pure and severe atrophy of the cerebellar vermis and hemispheres (Figure2), whereas brainstem and cerebral hemispheres are spared. ${ }^{44,53,113,114}$ This is strikingly similar to that observed in SCA5 patients. ${ }^{110}$ SCA1, SCA2 (Figure3) and SCA7 patients also present with various degrees of cerebellar atrophy. SCA3/MJD, however, is characterised by severe pontine and spinal atrophy with moderate cerebellar atrophy. These features correlate well with the neuropathological observations.

\section{Neuropathological lesions}

Each genetic sub-form has a strikingly different neuropathological profile (Table4). ${ }^{115}$ SCA 6 patients have severe Purkinje cell loss with moderate degeneration of cells in the granular layer and inferior olives. SCA1 patients have the most widespread cell loss. Their neuropathological profile can resemble OPCA. Olivocerebellar and dentatorubral tracts as well as the posterior column are affected. Atrophy of cranial nerves (mostly the third and 12th) and severe Purkinje cell loss (vermis) are also noted. ${ }^{115}$ Cell loss is mild in the substantia nigra, the locus coeruleus and the Clarke's column. ${ }^{52,116}$ The SCA2 profile is considered typical of OPCA since the inferior olive, substantia nigra, cerebellum (severe Purkinje cells loss) and pontine nuclei are affected. ${ }^{117}$ It can be distinguished from SCA1, however, since the superior cerebellum peduncles are spared and the substantia nigra 
A
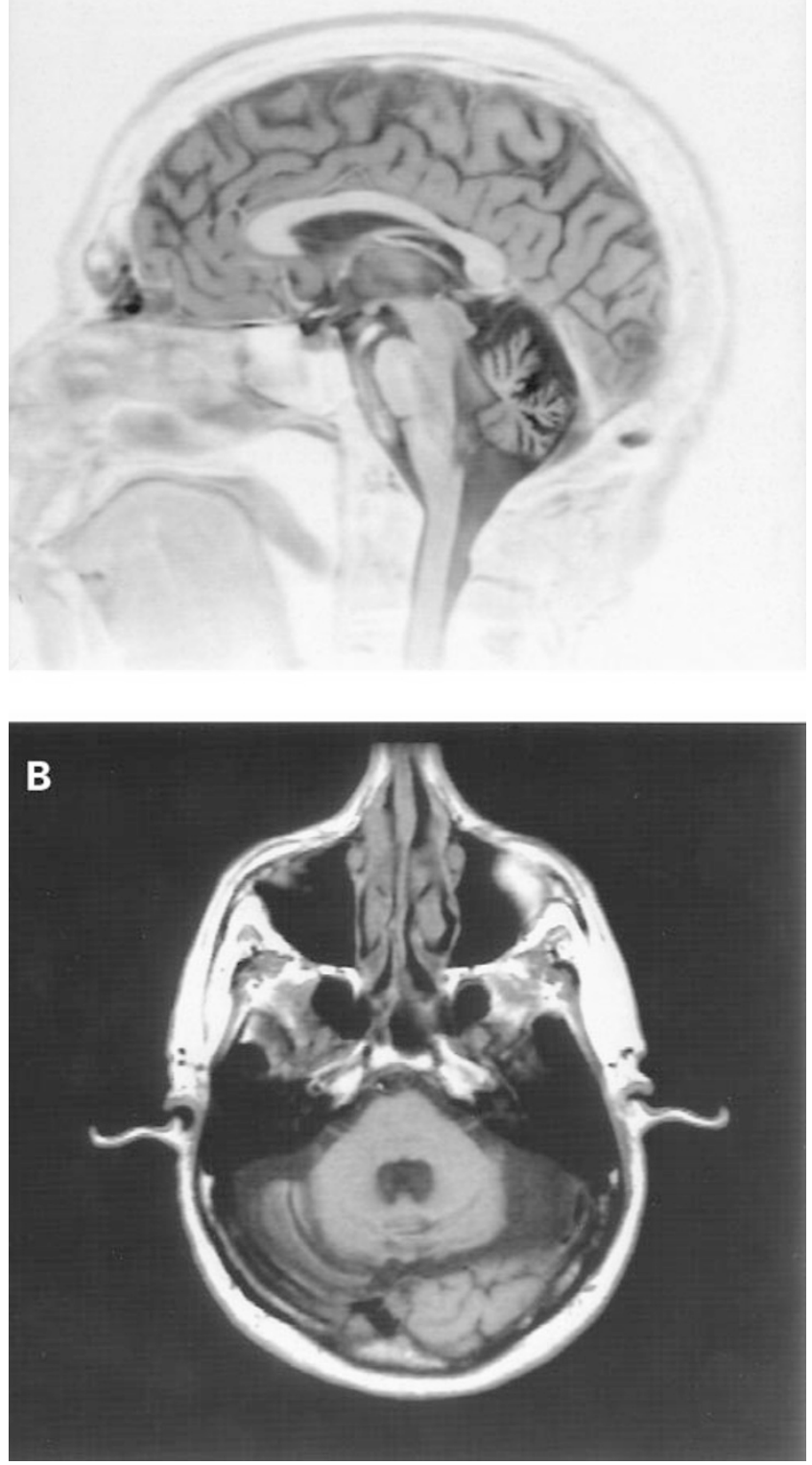

Figure 2 MRI of a SCA6 patient after 10 years' disease $^{53}$ A Inversion Recovery T2 weighted (TR 4000 ms; TE $17 \mathrm{~ms}$ ) image on a strictly mid-sagittal section with major cerebellar atrophy and preserved brainstem and cerebrum; B Spin Echo T1 weighted (TR $640 \mathrm{~ms}$; TE $11 \mathrm{~ms}$ ) image on axial section through the pons and the cerebellum. The cerebellar vermis and cortex are severely atrophied, the pons is spared. (by permission of Dr Ayman Tourbah)

\section{A}
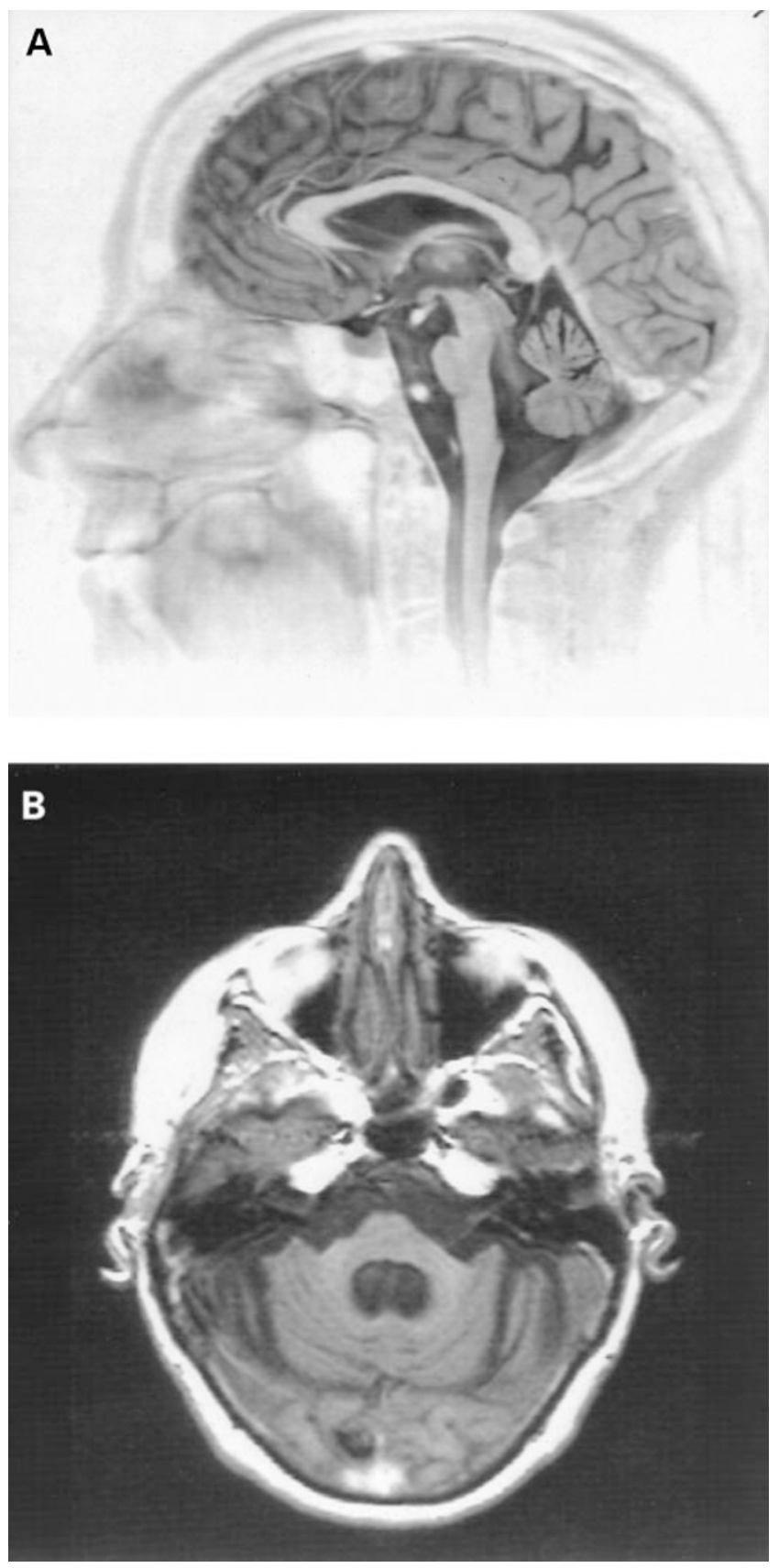

Figure 3 Cephalic MR of a SCA2 patient with 10 years' disease. A Sagittal plane, inversion Recovery $\mathrm{T} 2$ weighted ( $\mathrm{TR}=5000 \mathrm{~ms}$, TE $=17 \mathrm{~ms}, \mathrm{Tl}=140 \mathrm{~ms}$ ) showing a global atrophy of the pons, predominantly posterior, associated to a discrete bulbar and cerebellar vermian superior atrophy. B Spin Echo T1 weighted (TR $=2000 \mathrm{ms,}$ $\mathrm{TE}=11 \mathrm{~ms}, \mathrm{TI}=800 \mathrm{~ms}$ ) image on axial section through the middle of the pons showing its atrophy as well as on the cerebellar hemispheres associated with the dilatation of the fourth ventricle. (by permission of Dr Ayman Tourbah) 
Table 4 Neuropathological features associated with SCA mutations (A Dürr, C Duyckaerts, unpublished data, 1999 and ${ }^{52,115,117,147,176}$ )

\begin{tabular}{|c|c|c|c|c|c|}
\hline Structure & SCA1 & SCA2 & SCA3/MJD & SCA6 & SCA7 \\
\hline Cerebral cortex & - & + & - & - & $(+)$ \\
\hline White matter & - & + & - & - & - \\
\hline Globus pallidus & texternal & + & +Hinternal & - & + \\
\hline Sub-thalamic nucleus & + & + & + & - & ++ \\
\hline Substantia nigra & + & + & + & - & + \\
\hline Pontine nuclei & + & $+H$ & + & - & + \\
\hline Inferior olivary & ++ & $+H$ & - & $(+)$ & $+H$ \\
\hline Purkinje cells & + & + & $(+)$ & $+1+$ & + \\
\hline Dentate nucleus & + & - & + & $(+)$ & + \\
\hline Spinocerebellar tracts & ++ & - & $+H$ & - & + \\
\hline Cortico-spinal tracts & - & - & $(+)$ & & + \\
\hline Anterior horn & + & + & + & - & + \\
\hline Posterior column & + & $+H$ & + & - & + \\
\hline
\end{tabular}

- spared; (+) slight alteration; + discrete; ++ moderate; ++ severe atrophy.

severely lesioned. The cerebral cortex is also often affected. In SCA3/MJD, lesions of the basal ganglia (internal pallidum, sub-thalamic nucleus and substantia nigra), the intermediolateral column and Clarke's column are more severe than in SCA1, but the Purkinje cells, the inferior olives and posterior column are spared. This profile varies as a function of CAG repeat size. ${ }^{52}$ Given the differences between the neuropathological profiles of SCA1 and SCA3/MJD patients, it is surprising that patients with these mutations present with the same variety of clinical signs associated with cerebellar ataxia. $^{52}$

In SCA7 (ADCA typell) patients, spinocerebellar, olivocerebellar and efferent cerebellar tracts are severely affected. Purkinje cells, granule cells and neurons in the dentate nuclei also degenerate. Cell lossisalso observed in the inferior olive, the substantia nigra and basis pontis, whereas the thalamus and striatum are spared. The distinctive features of ADCA II are involvement of optic pathways and the retina. The pregeniculate visual pathways are affected, probably as a consequence of retinal degeneration. Pathological examination of the retina shows early degeneration of the photoreceptors, the bipolar and granular cells, particularly in the foveal and parafoveal regions. Later, the inner retinal layers are affected with patchy loss of epithelial pigment cells and penetration of pigmented cells into the retinal layers. ${ }^{118}$

\section{Factors influencing intrafamilial clinical variability}

The major factors that influence phenotype are the size of the repeat expansion and disease duration at examination.

\section{Factors influencing age at onset}

In all subforms of SCA, age at onset varies among patients from the same family and correlates negatively with CAG repeat size, as in other trinucleotide repeat disorders. The repeat length explains $50-80 \%$ of the variability of age at onset (Figure 1), indicating that other factors influence pathogenesis. Its effect (the slope of regression curve), however, differs for each mutation and suggests that the protein context also affects pathogenesis.
Several attempts have been made to identify other factors influencing age at onset. A gender effect ${ }^{119}$ was reported to be a contributing factor in SCA3/MJD, but this observation was not found by other groups. ${ }^{120,121}$ At least one other familial factor is postulated in this disease ${ }^{122}$ and the number of CAG repeats of the normal allele has also been reported to influence age at onset. ${ }^{52}$ Homozygosity is reported to cause earlier onset in SCA2, ${ }^{26}$ SCA3/MJD ${ }^{119,123,124}$ and SCA6, ${ }^{101,125,126}$ suggesting that allelic dosage influences clinical onset. This was not observed, however, in HD. 127,128

\section{Factors underlying variability of phenotype and progression rate}

Part of the variability in phenotype has been explained by a bias resulting from clinical evaluation of patients with different disease durations. The frequencies of decreased vibration sense, Babinski sign, ophthalmoplegia, amyotrophy and sphincter disturbances are positively correlated with disease duration in ADCA-I families. ${ }^{129}$ Clinical signs such as dysphagia or sphincter disturbances increase with disease duration in SCA $2,{ }^{71}$ SCA $3 / M_{J D}{ }^{52}$ and SCA $7,{ }^{75}$ as does dysarthria in SCA6 patients. ${ }^{53}$

CAG repeat size, not only affects age at onset, it also has a major effect on phenotype expression. The rate of progression until death, of SCA1, ${ }^{130}$ SCA3/MJD ${ }^{131}$ and SCA $7^{75}$ patients, is negatively correlated with repeat size. Indeed, large SCA7 expansions are associated with juvenile forms of the disease that are more severe and progress more rapidly than adult forms. ${ }^{56,75,76,78}$ The number of CAG repeats also affects the frequency of several clinical signs and partly accounts for phenotypic variability among patients. In SCA3/ MJD patients, the frequency of pyramidal signs increases with the size of the expanded repeat, whereas the frequency of altered vibration sense decreases. ${ }^{52}$ Late-onset SCA3 patients often present with peripheral neuropathy (areflexia and amyotrophy) and have small CAG repeats. ${ }^{52}$ Some patients with small SCA3/MJD expansions can present with late onset DOPA-responsive Parkinsonism. ${ }^{132}$ The presence of mild axonal neuropathy helps to distinguish these patients 
from idiopathic Parkinson's disease. On the other hand, SCA3 patients with large expansions are mostly dystonic. Some patients with amyotrophic lateral sclerosis-like presentation are diagnosed SCA1 and carry large expansions. They constitute an extreme clinical presentation of SCA1. In SCA2, myokimia, myoclonus, dystonia and fasciculations are more frequently observed in patients carrying large expansions. ${ }^{71}$ SCA2 patients with large expansions manifest chorea and dementia as prominent features. In SCA7, the frequency of pyramidal signs, ophthalmoplegia and decreased visual acuity increases with repeat size. ${ }^{75}$ In SCA6, given the slow progression of the disease, only patients with the largest expansions, associated with earlier onset, develop associated signs that can overlap with those found in ADCA typel. ${ }^{53}$ Interestingly, cardiac failure was observed in patients with very large $\mathrm{SCA} 2^{74}$ and $\mathrm{SCA} 7^{78}$ expansions, indicating the possibility of extra-neurological involvement in extreme cases.

\section{Physiopathology of ADCA and other neurodegenerative diseases caused by polyglutamine expansions}

The expression of both mutated and normal proteins, and the dominant nature of the mutation suggest that the disease is the result of a gain of function that occurs at the protein level and increases with repeat size after a threshold of approximately $40 \mathrm{glutamines}$. The mechanism of this gain of function is still not elucidated, but evidence suggests that the pathological expansion confers a toxic property on the protein.

Animal and cellular models have been very useful for exploring the pathophysiology of triplet repeat disorders. Direct expression of a human CDNA encoding the SCA1 and SCA3 genes with expanded CAG repeats, and expression of an isolated expanded CAG repeat, cause Purkinje cell degeneration and ataxia in transgenic mice. ${ }^{133,134}$ That expansion alters the conformation of polyglutamine tracts as initially suggested by the detection of long repeats using the 1C2 antibody. ${ }^{135}$ This could explain the formation of insoluble intranuclear aggregates in an animal model of $\mathrm{HD}^{136}$ and in transgenic models of ataxia. Neuronal intranuclear inclusions (NI) have also been detected in the brains of patients with several polyglutamine diseases (HD, DRPLA, SCA1, SCA3/MJD, SCA7) as well as in animal or cellular models, ${ }^{137}$ and appear to constitute a common signature of this group of disorders (Figure4). Cytoplasmic non-ubiquitinated aggregates have also been observed in SCA6 brains and in cultured cells transfected with full length CACNA1A with pathological expansion. ${ }^{138}$

How are NI formed? A number of hypotheses have been proposed, but none has been demonstrated in vivo: nonconvalent interactions with other proteins, transglutamination, ${ }^{139,140}$ formation of multimeric aggregates by hydrogenbonded polar-zippers. ${ }^{141}$ In vitro, the fibrillary appearance of

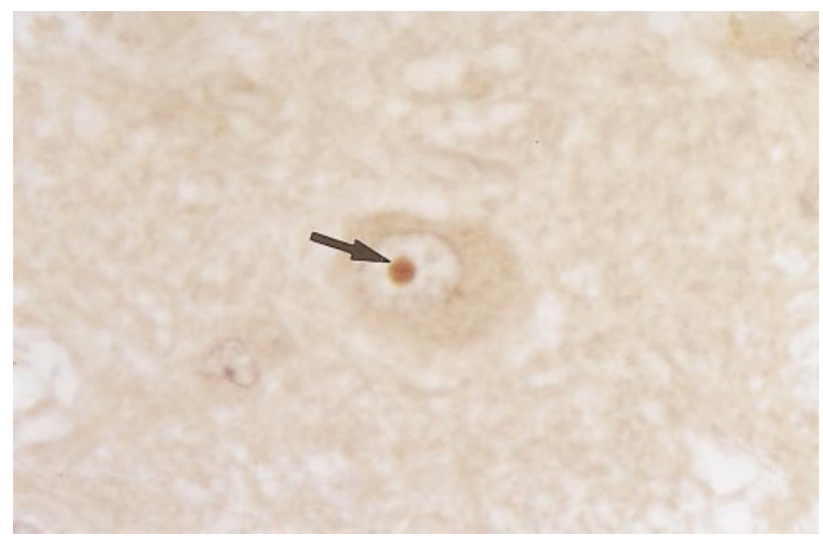

Figure 4 Intranuclear inclusions (NIs) in the inferior olive of a SCA7 patient carrying 85 CAG repeats $(\times 250)$. The inclusion has been labelled with the $1 C 2$ antibody $^{135}$ and revealed by the peroxidase/anti-peroxidase technique, with diaminobenzidine as the chromogen. Staining of the nucleus by Harris haematoxylin. These NIs are also detected with an anti-ubiquitine antibody (data not shown). (by permission of Professor Charles Duyckaerts)

inclusions on electron microscopy and the green birefringence after staining with Congo red, both of which are reminiscent of amyloid, are consistent with the polar zipper hypothesis. Polyglutamine expansions are also good substrates for transglutaminases in vitro, ${ }^{142}$ and the presence of transglutaminase inhibitors prevented aggregate formation in COS-7 cells transiently tran sfected with truncated forms of the DRPLA or HD gene with expansions. ${ }^{143,144}$

The major question remains whether nuclear aggregates are a cause or a consequence of the pathogenic process. They appear before neuronal loss and before expression of the phenotype in a mouse model of HD. ${ }^{136}$ It was then suggested that they are a good hallmark of the disease, since their density is correlated to the expansion size. ${ }^{145}$ However, they are also present in epithelial cells of a drosophila model of SCA3 in which there is no neuronal death or phenotype, ${ }^{146}$ and have been detected in non-affected neuronal tissues in an SCA7 patient, ${ }^{147}$ and in peripheral tissues in an HD mouse model, ${ }^{148}$ indicating that their presence is not sufficient to cause death and/or phenotype. A recent although controversial ${ }^{149}$ study showed, however, that visible aggregates are not a prerequisite for pathogenesis in a SCA1 mouse model ${ }^{150}$ and that neuronal death is not correlated with $\mathrm{NI}$ formation in animal and cellular models of HD. ${ }^{144,151}$ It was consequently proposed that $\mathrm{NI}$ may reflect a cell defence rather than a pathogenic mechanism. ${ }^{152}$

Is targeting to the nucleus a crucial step in pathogenesis and how does it occur? Neuronal degeneration does not occur when mutant ataxin-1 ${ }^{150}$ or mutant huntingtin ${ }^{144}$ are targeted to the cytoplasm - two experiments again criticised. ${ }^{149}$ The nucleus may therefore be a primary site of the degenerative process. The pathological proteins might be targeted to the nucleus either by nuclear transport or passive 
transport following proteolytic cleavage. Evidence for aberrant proteolysis come from experiments in which truncated proteins with polyglutamine expansions appeared more prone than full length proteins to aggregate or cause cell death by apoptosis. ${ }^{134,153-155}$ In addition, truncated fragments that may result from caspase- 1 cleavage ${ }^{156}$ have been detected in nuclear aggregates of HD patients. ${ }^{157}$ The question remains whether this cleavage refers to the normal function of the proteins, to abnormal degradation, or to a protective response of the cell to these proteins. Elucidation of the proteolytic processing mechanisms would be desirable.

Interestingly, several neurodegenerative diseases including polyglutamine diseases as well as Alzheimer's disease, Parkinson's disease and prion-generated diseases result from the accumulation of misfolded proteins and associated cytotoxicity. ${ }^{158}$ Indeed, experiments have revealed a characteristic that is reminiscent of prions, the recruitment of full-length proteins by truncated molecules in HD, DRPLA and SCA3. ${ }^{143,153,154}$ More recently, expanded ataxin 1, atrophin and androgen receptor have been co-localised to the proteasome, a proteolytic system, and several studies have shown redistribution of the proteasome complex to NI, ${ }^{159-161}$ which are ubiquitinated, one of the primary events in the proteasome degradation pathway. This might lead to the disorganisation of the nuclear machinery, perhaps by sequestering of transcription factors such as the TATA-binding protein, ${ }^{162}$ other regulatory proteins or RNA, ${ }^{163,164}$ and finally to cell death. The redistribution of the promyelocytic leukaemia protein in the nucleus of SCA1 patients is consistent with this hypothesis. ${ }^{164}$

The proteins with expanded polyglutamine tracts are widely expressed in the nervous system of patients, contrasting with the relatively selective pattern of degeneration observed in each disorder. Several studies have revealed that the degree of somatic mosaicism detected in the nervous system does not account for the selectivity of neuronal death, ${ }^{86}$ which might result from specific interactions of the mutated protein with protein partners expressed preferentially in the regions affected by the respective diseases and/or from abnormal expression levels. Several protein partners have been identified, some of which have greater affinity for the expanded protein than the normal form. This is particularly the case with the leucine-rich acidic nuclear protein that interacts with ataxin-1 and co-localises with NI. ${ }^{163}$ Selectivity is also a function of the progression of the disease, since infantile and adult cases can have different patterns of degeneration.

\section{Diagnostic implications}

Identification of ADCA genes and their mutations has now changed clinical practice because of the possibility of direct molecular diagnosis without which correct classification and diagnosis is extremely difficult. Molecular analysis for trans- lated CAG repeat expansions permits routine diagnostic testing of individuals who al ready present with symptoms of the disease. Molecular analysis is also useful to distinguish disorders which are clinically similar or which can be confused with other diseases because of their extremely variable clinical presentation.

DNA testing in asymptomatic at-risk individuals, however, raises many difficult ethical issues for severe adult-onset disorders for which no treatment can be proposed. The international guidelines elaborated for Huntington's disease should also be followed for ADCA. ${ }^{165}$ The number of CAG repeats on the expanded allele is a major factor which accounts for $50-80 \%$ of the variability of the age at onset. However, individual variations are important and age at onset cannot be precisely predicted from the number of CAG repeats.

Molecular diagnosis of isolated cases is also crucial. SCA6 and SCA2 were first to provide a molecular basis for some cases with idiopathic sporadic ataxia. ${ }^{45,71}$ Family histories can be missed if the transmitting parent dies before onset of symptoms or is still asymptomatic because of marked anticipation. De novo mutations, as in SCA7, ${ }^{68}$ also appear as isolated cases. Finally, care should also be taken to deduct alleles with more than 100 repeats, reported in juvenile or infantile forms of SCA2 and SCA7, ${ }^{56,74-76,78,166}$ that might be difficult to amplify and visualise.

\section{Conclusions}

Discovery of the mutations underlying ADCA and the correlations between CAG repeat length and clinical or neuropathological features of genetically specific sub-forms of the disease have simplified the molecular diagnosis and permit analysis of uniformly classified patients, a necessary step to the development of a precise nosology and a better follow-up of the patients. Although it is often impossible to identify the SCA mutation on the basis of clinical criteria since phenotype depends on the locus, the size of the repeat expansion, the duration of the disease and other unknown factors, analysis of the molecular and clinical characteristics have revealed group differences that will be helpful for understanding the history and evolution of patients with ADCA.

The cause of the molecular instability and the pathophysiological consequences of the expanded polyglutamine tract remain unknown, and therapeutic intervention requires elucidation of the underlying pathogenic mechanism. Animal and cellular models are helping to understand processing of the pathological proteins and to identify their molecular partners. The recent report of a new type of mutation, an untranslated CTG repeat sequence at the SCA8 locus, has complicated this picture and suggests that a different mechanism of toxicity might be involved. A dominant negative effect, a deleterious effect on the transcription of another gene close to this locus, or an abnormal interaction at the 
RNA level are possible mechanisms but nothing is known as yet on this novel form of ADCA.

\section{Acknowledgements}

The authors are grateful to Dr M erle Ruberg and Anne-Sophie Lebre for critical reading of the manuscript. The authors' work is financially supported by the VERUM foundation, a BIOMED Concerted Action of the European Economic Community, the Institut National de la Santé et de la Recherche Médicale and the Association pour le Dével oppement de la Recherche sur les Maladies Génétiques Neurologiques et Psychiatriques. GS held a fellowship from the Fondation pour la Recherche Médicale.

\section{References}

1 Holmes G: An attempt to classify cerebellar disease, with a note on Marie's hereditary cerebellar ataxia. Brain 1907; 30: 545-567.

2 Greenfield JG: The Spino-cerebellar Degenerations. Blackwell: Oxford, 1954.

3 Konigsmark BW, Weiner LP: The olivopontocerebellar atrophies: a review. Medicine (Baltimore) 1970; 49: 227-241.

4 Harding AE: The clinical features and classification of the late onset autosomal dominant cerebellar ataxias. A study of $11 \mathrm{fami}$ lies, including descendants of the Drew family of Walworth. Brain 1982; 105: 1-28.

5 Harding AE (ed): The Hereditary Ataxias and Related Disorders. Churchill Livingston: Edinburgh, 1984.

6 Harding AE: Clinical features and classification of inherited ataxias. Adv Neurol 1993; 61: 1-14.

7 Friedreich $\mathrm{N}$ : Über degenerative Atrophie der spinalen Hinterstränge. Virchows Arch Pathol Anat 1863; 27: 1-26.

8 Harding AE: Friedreich's ataxia: a clinical and genetic study of 90 families with an analysis of early diagnostic criteria and intrafamilial clustering of clinical features. Brain 1981; 104: 589-620.

9 Campuzano V, Montermini L, Molto MD et al: Friedreich's ataxia: autosomal recessive disease caused by an intronic GAA triplet repeat expansion. Science 1996; 271: 1423-1427.

10 Yakura H, Wakisaka A, Fujimoto S, Itakura K: Hereditary ataxia and HLA genotypes. N Engl J Med 1974; 291: 154-155.

11 Gispert S, Twells R, Orozco G et al: Chromosomal assignment of the second locus for autosomal dominant cerebellar ataxia (SCA2) to chromosome12q23-24.1. Nat Genet 1993; 4: 295-299.

12 Takiyama Y, Nishizawa M, Tanaka $\mathrm{H}$ et al: The gene for MachadoJoseph disease maps to human chromosome14q. Nat Genet 1993; 4: 300-304.

13 Stevanin G, Le Guern E, Ravise N et al: A third locus for autosomal dominant cerebellar ataxia typel maps to chromosome14q24.3-qter: evidence for the existence of a fourth locus. Am J Hum Genet 1994; 54: 11-20.

14 Flanigan K, Gardner K, Alderson K et al: Autosomal dominant spinocerebellar ataxia with sensory axonal neuropathy (SCA4): clinical description and genetic localization to chromosome16q22.1. Am J Hum Genet 1996; 59: 392-399.

15 Benomar A, Krols L, Stevanin G et al: The gene for autosomal dominant cerebellar ataxia with pigmentary macular dystrophy maps to chromosome3p12-p21.1. Nat Genet 1995; 10: 84-88.

16 Gouw LG, Kaplan CD, Haines JH et al: Retinal degeneration characterizes a spinocerebellar ataxia mapping to chromosome3p. Nat Genet 1995; 10: 89-93.
17 Holmberg M, Johansson J, Forsgren L, Heijbel J, Sandgren O, Holmgren G: Localization of autosomal dominant cerebellar ataxia associated with retinal degeneration and anticipation to chromosome3p12-p21.1. Hum Mol Genet 1995; 4: 1441-1445.

18 Ranum LP, Schut LJ, Lundgren JK, Orr HT, Livingston DM: Spinocerebellar ataxia type 5 in a family descended from the grandparents of President Lincoln maps to chromosome11. Nat Genet 1994; 8: 280-284.

19 Worth PF, Giunti P, Gardner-Thorpe CG, Dixon PH, Davis MB, Wood NW: Autosomal dominant cerebellar ataxia typellI: linkage of a large British family to a $7.6 \mathrm{cM}$ region (SCA 11) on chromosome15q14-21.3. Am J Hum Genet 1999; 65: 420-426.

20 Zhuchenko O, Bailey J, Bonnen P et al: Autosomal dominant cerebellar ataxia (SCA6) associated with small polyglutamine expansions in the alpha ${ }_{1 \mathrm{~A}}$-voltage-dependent calcium channel. Nat Genet 1997; 15: 62-69.

$21 \mathrm{Zu} \mathrm{L}$, Figueroa KP, Grewal R, Pulst SM: Mapping of a new autosomal dominant spinocerebellar ataxia to chromosome 22 . Am J Hum Genet 1999; 64: 594-599.

22 Matsuura T, Madhureeta A, Mehrdad K, Bachinski LL, Zoghbi HY, Ashizawa T: Mapping of the gene for a novel spinocerebellar ataxia with pure cerebellar signs and epilepsy. Ann Neurol 1999; 45: 407-411.

23 Orr HT, Chung MY, Banfi S et al: Expansion of an unstable trinucleotide CAG repeat in spinocerebellar ataxia type1. Nat Genet 1993; 4: 221-226.

24 Imbert G, Saudou F, Yvert G et al: Cloning of the gene for spinocerebellar ataxia 2 reveals a locus with high sensitivity to expanded CAG/glutamine repeats. Nat Genet 1996; 14: 285-291.

25 Pulst SM, Nechiporuk A, Nechiporuk T et al: Moderate expansion of a normally biallelic trinucleotide repeat in spinocerebellar ataxia type2. Nat Genet 1996; 14: 269-276.

26 Sanpei K, Takano H, Igarashi S et al: Identification of the spinocerebellar ataxia type 2 gene using a direct identification of repeat expansion and cloning technique, DIRECT. Nat Genet 1996; 14: 277-284.

27 Kawaguchi Y, Okamoto T, Taniwaki M et al: CAG expansion in a novel gene for Machado-Joseph disease at chromosome14q32.1. Nat Genet 1994; 8: 221-227.

28 Cancel G, Abbas N, Stevanin G et al: Marked phenotypic heterogeneity associated with expansion of a CAG repeat sequence at the spinocerebellar ataxia3/M achado-Joseph disease locus. Am J Hum Genet 1995; 57: 809-816.

29 Schols L, Vieira-Saecker AM, Schols S, Przuntek H, Epplen JT, Riess O: Trinucleotide expansion within the MJD1 gene presents clinically as spinocerebellar ataxia and occurs most frequently in German SCA patients. Hum Mol Genet 1995; 4: 1001-1005.

30 David G, Abbas N, Stevanin G et al: Cloning of the SCA7 gene reveals a highly unstable CAG repeat expansion. Nat Genet 1997; 17: $65-70$.

31 Del-Favero J, Krols L, Michalik A et al: Molecular genetic analysis of autosomal dominant cerebellar ataxia with retinal degeneration (ADCA typell) caused by CAG triplet repeat expansion. Hum Mol Genet 1998; 7: 177-186.

32 Koob MD, Benzow KA, Bird TD, Day JW, Moseley ML, Ranum LPW: Rapid cloning of expanded trinucleotide repeat sequences from genomic DNA. Nat Genet 1998; 18: 72-75.

33 Mandel J-L: Breaking the rule of three. Nature 1997; 386: 767-769.

34 Pujana MA, Volpini V, Gratacos $M$ et al: Uncloned expanded CAG/CTG repeat sequences in autosomal dominant cerebellar ataxia (ADCA) detected by the repeat expansion detection (RED) method. J Med Genet 1998; 35: 99-102.

35 Stevanin G, Trottier Y, Cancel G et al: Screening for proteins with polyglutamine expansions in autosomal dominant cerebellar ataxias. Hum Mol Genet 1996; 5: 1887-1892.

36 Koob MD, Moseley ML, Schut LJ et al: An untranslated CTG expansion causes a novel form of spinocerebellar ataxia (SCA8). Nat Genet 1999; 21: 379-384. 
37 Pratt RTC (ed): The Genetics of Neurological Disorders. Oxford University Press: London, 1967.

38 Hirayama K, Takayanagi T, Nakamura R et al: Spinocerebellar degenerations in Japan: a nationwide epidemiological and clinical study. Acta Neurol Scand 1994; 153 (Suppl): 1-22.

39 Orozco G, Estrada R, Perry TL et al: Dominantly inherited olivopontocerebellar atrophy from eastern Cuba. Clinical, neuropathological, and biochemical findings. J Neurol Sci 1989; 93: 37-50

40 Sequeiros J Coutinho P: Epidemiology and clinical aspects of Machado-Joseph disease. Adv Neurol 1993; 61: 139-153.

41 Benomar A, Meggouh F, Didierjean O et al: Autosomal dominant cerebellar ataxia typel in Morocco: presence of the SCA1 and SCA3/MJD mutations. Eur J Neurol 1996; 3: 369-372.

42 Silveira I, Lopes-Cendes I, Kish S et al: Frequency of spinocerebellar ataxia type 1, dentatorubropallidoluysian atrophy, and Machado-Joseph disease mutations in a large group of spinocerebellar ataxia patients. Neurology 1996; 46: 214-218.

43 Leggo J, Dalton A, Morrison PJ et al: Analysis of spinocerebellar ataxia types 1, 2, 3, and 6, dentatorubral-pallidoluysian atrophy, and Friedreich's ataxia genes in spinocerebellar ataxia patients in the UK. J Med Genet 1997; 34: 982-985.

44 Schols L, Kruger R, Amoiridis G, Przuntek H, Epplen JT, Riess O: Spinocerebellar ataxia type6: genotype and phenotype in German kindreds. J Neurol Neurosurg Psychiatr 1998; 64: 67-73.

45 Schols L, Amoiridis G, Buttner T, Przuntek H, Epplen JT, Riess O: Autosomal dominant cerebellar ataxia: phenotypic differences in genetically defined subtypes? Ann Neurol 1997; 42: 924-932.

46 Riess O, Laccone FA, Gispert S et al: SCA2 trinucleotide expansion in German SCA patients. Neurogenetics 1997; 1: 59-64

47 Silveira I, Coutinho P, Maciel P et al: Analysis of SCA1, DRPLA, MJD, SCA2, and SCA6 CAG repeats in 48Portuguese ataxia families. Am J Med Genet 1998; 81: 134-138.

48 Zhou YX, Wang GX, Tang BS et al: Spinocerebellar ataxia type2 in China: molecular analysis and genotype- phenotype correlation in nine families. Neurology 1998; 51: 595-598.

49 Mizushima K, Watanabe M, Abe K et al: Analysis of spinocerebellar ataxia type 2 in Gunma Prefecture in Japan: CAG trinucleotide expansion and clinical characteristics. J Neurol Sci 1998; 156: 180-185.

50 Takano H, Cancel G, Ikeuchi $\mathrm{T}$ et al: Population genetics of dominantly inherited spinocerebellar ataxias with CAG repeat expansions in Japanese and Caucasian: tight association of the prevalence rates with the frequencies of intermediate alleles. Am J Hum Genet 1998; 63: 1060-1066.

51 Trojano L, Chiacchio L, Grossi D et al: Determinants of cognitive disorders in Autosomal Dominant Cerebellar Ataxia type1. J Neurol Sci 1998; 157: 162-167.

52 Durr A, Stevanin G, Cancel G et al: Spinocerebellar ataxia3 and Machado-Joseph disease: clinical, molecular and neuropathological features. Ann Neurol 1996; 39: 490-499.

53 Stevanin G, Durr A, David G et al: Clinical and molecular features of spinocerebellar ataxia type6. Neurology 1997; 49: 1243-1246.

54 Matsuyama Z, Kawakami H, Maruyama H et al: Molecular features of the CAG repeats of spinocerebellar ataxia 6 (SCA6). Hum Mol Genet 1997; 6: 1283-1287.

55 Pareyson D, Gellera C, Castellotti B et al: Clinical and molecular studies of 73 Italian families with autosomal dominant cerebellar ataxia typel: SCA1 and SCA2 are the most common genotypes.J Neurol 1999; 246: 389-393.

56 Pujana MA, Corral J, Gratacos M et al: Spinocerebellar ataxias in Spanish patients: genetic analysis of familial and sporadic cases. The Ataxia Study Group. Hum Genet 1999; 104: 516-522.

57 Wakisaka A, Sasaki H, Takada A et al: Spinocerebellar ataxia 1 (SCA1) in the Japanese in Hokkaido may derive from a single common ancestry. J Med Genet 1995; 32: 590-592.

58 Didierjean O, Cancel G, Stevanin G et al: Linkage disequilibrium at the SCA2 locus. J Med Genet 1999; 36: 415-417.
59 Stevanin G, Cancel G, Didierjean O et al: Linkage disequilibrium at the Machado-Joseph disease/Spinal cerebellar ataxia 3 locus: evidence for a common founder effect in French and PortugueseBrazilian families as well as a second ancestral PortugueseAzorean mutation. Am J Hum Genet 1995; 57: 1247-1250.

60 Takiyama Y, Igarashi S, Rogaeva EA et al: Evidence for intergenerational instability in the CAG repeat in the MJD1 gene and for conserved haplotypes at flanking markers amongst Japanese and Caucasian subjects with Machado-Joseph disease. Hum Mol Genet 1995; 4: 1137-1146.

61 Gaspar C, Lopes-Cendes I, DeStefano AL et al: Linkage disequilibrium analysis in Machado-Joseph disease patients of different ethnic origins. Hum Genet 1996; 98: 620-624.

62 Endo K, Sasaki H, Wakisaka A et al: Strong linkage disequilibrium and haplotype analysis in Japanese pedigrees with MachadoJoseph disease. Am J Med Genet 1996; 67: 437-444.

63 Stevanin G, Lebre AS, Mathieux C et al: Linkage disequilibrium between the spinocerebellar ataxia3/Machado-Joseph disease mutation and two intragenic polymorphisms, one of which, X359Y, affects the stop codon. Am J Hum Genet 1997; 60: 1548-1552.

64 Stevanin G, David G, Dürr A et al: Multiple origins of the spinocerebellar ataxia 7 (SCA7) mutation revealed by linkage disequilibrium studies with closely flanking markers, including an intragenic polymorphism $\left(\mathrm{G}^{3145} \mathrm{TG} / \mathrm{A}^{3145} \mathrm{TG}\right)$. Eur J Hum Genet 1999; 7: 889-896.

65 Dichgans M, Schols L, Herzog J et al: Spinocerebellar ataxia type6: evidence for a strong founder effect among German families. Neurology 1999; 52: 849-851.

66 Rosenberg RN: Joseph disease: an autosomal dominant motor system degeneration. Adv Neurol 1984; 41: 179-193.

67 Rosenberg RN: Machado-Joseph disease: an autosomal dominant motor system degeneration. Mov Disord 1992; 7: 193-203.

68 Stevanin G, Giunti P, Belal S et al: De novo expansion of intermediate alleles in spinocerebellar ataxia 7. Hum Mol Genet 1998; 7: 1809-1813.

69 Goldberg YP, M cM urray CT, Zeisler J et al: Increased instability of intermediate alleles in families with sporadic Huntington disease compared to similar sized intermediate alleles in the general population. Hum Mol Genet 1995; 4: 1911-1918.

70 Takiyama Y, Sakoe K, Soutome M et al: Single sperm analysis of the CAG repeats in the gene for Machado-Joseph disease (MJD1): evidence for non-Mendelian transmission of the MJD1 gene and for the effect of the intragenic CGG/GGG polymorphism on the intergenerational instability. Hum Mol Genet 1997; 6: 1063-1068.

71 Cancel G, Dürr A, Didierjean O et al: Molecular and clinical correlations in spinocerebellar ataxia2: a study of 32 families. Hum Mol Genet 1997; 6: 709-715.

72 Jodice $C$, Mantuano $E$, Veneziano $L$ et al: Episodic ataxia type2 (EA2) and spinocerebellar ataxia type6 (SCA6) due to CAG repeat expansion in the CACNA1A gene on chromosome19p. Hum Mol Genet 1997; 6: 1973-1978.

73 van Schaik IN, Jobsis GJ, Vermeulen M, Keizers H, Bolhuis PA, de Visser M: Machado-Joseph disease presenting as severe asymmetric proximal neuropathy. J Neurol Neurosurg Psychiatr 1997; 63: $534-536$.

74 Babovic-Vuksanovic D, Snow K, Patterson MC, Michels VV: Spinocerebellar ataxia type2 (SCA 2) in an infant with extreme CAG repeat expansion. Am J Med Genet 1998; 79: 383-387.

75 David G, Dürr A, Stevanin G et al: Molecular and clinical correlations in autosomal dominant cerebellar ataxia with progressive macular dystrophy (SCA7). Hum Mol Genet 1998; 7: 165-170.

76 Johansson J, Forsgren L, Sandgren O, Brice A, Holmgren G, Holmberg M: Expanded CAG repeat in Swedish Spinocerebellar ataxia type 7 (SCA7) patients: effect of CAG repeat length on the clinical manifestation. Hum Mol Genet 1998; 7: 171-176. 
77 Gouw LG, Castaneda MA, McKenna CK et al: Analysis of the dynamic mutation in the SCA7 gene shows marked parental effects on CAG repeat transmission. Hum Mol Genet 1998; 7: 525-532.

78 Benton CS, de Silva R, Rutledge SL, Bohlega S, Ashizawa T, Zoghbi HY: Molecular and clinical studies in SCA-7 define a broad clinical spectrum and the infantile phenotype. Neurology 1998; 51: 1081-1086.

79 Chung MY, Ranum LP, Duvick LA, Servadio A, Zoghbi HY, Orr HT: Evidence for a mechanism predisposing to intergenerational CAG repeat instability in spinocerebellar ataxia typel. Nat Genet 1993; 5: 254-258.

80 Quan F, Janas J, Popovich BW: A novel CAG repeat configuration in the SCA1 gene: implications for the molecular diagnosis of spinocerebellar ataxia type1. Hum Mol Genet 1995; 4: 2411-2413.

81 Stevanin G, David G, Abbas N et al: Spinocerebellar ataxia 7. In: Rubinsztein DC, Hayden M (eds). Trinucleotide Repeat Diseases. Bios Scientific Publishers Ltd: Oxford, 1998, pp 155-168.

82 Chong SS, McCall AE, Cota J et al: Gametic and somatic tissuespecific heterogeneity of the expanded SCA1 CAG repeat in spinocerebellar ataxia type1. N at Genet 1995; 10: 344-350.

83 Ueno S, Kondoh K, Kotani $Y$ et al: Somatic mosaicism of CAG repeat in dentatorubral-pallidoluysian atrophy (DRPLA). Hum Mol Genet 1995; 4: 663-666.

84 Lopes-Cendes I, Maciel P, Kish S et al: Somatic mosaicism in the central nervous system in spinocerebellar ataxia type 1 and Machado-Joseph disease. Ann Neurol 1996; 40: 199-206.

85 Takano H, Onodera O, Takahashi $\mathrm{H}$ et al: Somatic mosaicism of expanded CAG repeats in brains of patients with dentatorubralpallidoluysian atrophy: cellular population-dependent dynamics of mitotic instability. Am J Hum Genet 1996; 58: 1212-1222.

86 Cancel G, Gourfinkel-An I, Stevanin G et al: Somatic mosaicism of the CAG repeat expansion in spinocerebellar ataxia type3/ Machado-Joseph disease. Hum Mutat 1998; 11: 23-27.

87 Eichler EE, Holden J, Popovich BW et al: Length of uninterrupted CGG repeats determines instability in the FMR1 gene. Nat Genet 1994; 8: 88-94.

88 Kang S, Jaworski A, Ohshima K, Wells RD: Expansion and deletion of CTG repeats from human disease genes are determined by the direction of replication in E. coli. Nat Genet 1995; 10: $213-218$.

89 Wells RD, Parniewski P, Pluciennik A, Bacolla A, Gellibolian R, Jaworski A: Small slipped register genetic instabilities in Escherichia coli in triplet repeat sequences associated with hereditary neurological diseases. J Biol Chem 1998; 273: 19532-19541.

90 Maurer DJ, O'Callaghan BL, Livingston DM: Orientation dependence of trinucleotide CAG repeat instability in Saccharomyces cerevisiae. Mol Cell Biol 1996; 16: 6617-6622.

91 Schweitzer JK, Livingston DM: Expansions of CAG repeat tracts are frequent in a yeast mutant defective in Okazaki fragment maturation. Hum Mol Genet 1998; 7: 69-74.

92 Freudenreich $\mathrm{CH}$, Stavenhagen JB, Zakian VA: Stability of a CTG/ CAG trinucleotide repeat in yeast is dependent on its orientation in the genome. Mol Cell Biol 1997; 17: 2090-2098.

93 Ranen NG, Stine OC, Abbott $\mathrm{MH}$ et al: Anticipation and instability of IT-15 (CAG)n repeats in parent- offspring pairs with Huntington disease. Am J Hum Genet 1995; 57: 593-602.

94 Igarashi S, Takiyama Y, Cancel G et al: Intergenerational instability of the CAG repeat of the Machado-Joseph disease (MJD1) is affected by the genotype of the normal chromosome: implications for the molecular mechanisms of the instability of the CAG repeat. Hum Mol Genet 1996; 5: 923-932.

95 Goldberg YP, Andrew SE, Theilmann J et al: Familial predisposition to recurrent mutations causing Huntington's disease: genetic risk to sibs of sporadic cases. J Med Genet 1993; 30: 987-990.
96 Pearson CE, Ewel A, Acharya S, Fishel RA, Sinden RR: Human $\mathrm{MSH} 2$ binds to trinucleotide repeat DNA structures associated with neurodegenerative diseases. Hum Mol Genet 1997; 6: 1117-1123.

97 Gourdon G, Dessen P, Lia AS, Junien C, Hofmann-Radvanyi H: Intriguing association between disease associated unstable trinucleotide repeat and CpG island. Ann Genet 1997; 40: 73-77.

98 Yvert G, Mandel J-L: Variation on a trinucleotide theme. Nat Med 1999; 5: 383-384.

99 Benomar A, Le Guern E, Dürr A et al: Autosomal-dominant cerebellar ataxia with retinal degeneration (ADCA typell) is genetically different from ADCA typel. Ann Neurol 1994; 35: 439-444.

100 David G, Giunti P, Abbas $N$ et al: The gene for autosomal dominant cerebellar ataxia typell is located in a 5-cM region in 3p12-p13: genetic and physical mapping of the SCA7 locus. Am J Hum Genet 1996; 59: 1328-1336.

101 Ikeuchi T, Takano H, Koide R et al: Spinocerebellar ataxia type6: CAG repeat expansion in alphalA voltage-dependent calcium channel gene and clinical variations in Japanese population. Ann Neurol 1997; 42: 879-884.

102 Bürk K, Fetter M, Skalej M et al: Saccade velocity in idiopathic and autosomal dominant cerebral ataxia. J Neurol Neurosurg Psychiatr 1997; 62: 662-664.

103 Wadia N, Pang J, Desai J, Mankodi A, Desai M, Chamberlain S: A clinicogenetic analysis of six Indian spinocerebellar ataxia (SCA2) pedigrees; the significance of slow saccades in diagnosis. Brain 1998; 121: 2341-2355.

104 Lima L, Coutinho P: Clinical criteria for diagnosis of MachadoJoseph disease: report of a non-Azorena Portuguese family. Neurology 1980; 30: 319-322.

105 Schols L, Amoiridis G, Epplen JT, Langkafel M, Przuntek H, Riess $O$ : Relations between genotype and phenotype in German patients with the Machado-Joseph disease mutation. J Neurol Neurosurg Psychiatr 1996; 61: 466-470.

106 Matilla T, McCall A, Subramony SH, Zoghbi HY: Molecular and clinical correlations in spinocerebellar ataxia type 3 and Machado-Joseph disease. Ann Neurol 1995; 38: 68-72.

107 Giunti P, Sweeney MG, Harding AE: Detection of the MachadoJoseph disease/spinocerebellar ataxia three trinucleotide repeat expansion in families with autosomal dominant motor disorders, including the Drew family of Walworth. Brain 1995; 118: 1077-1085.

108 Maciel P, Gaspar C, DeStefano AL et al: Correlation between CAG repeat length and clinical features in Machado-Joseph disease. Am J Hum Genet 1995; 57: 54-61.

109 Maruyama H, Nakamura S, Matsuyama $Z$ et al: Molecular features of the CAG repeats and clinical manifestation of Machado-Joseph disease. Hum Mol Genet 1995; 4: 807-812.

110 Stevanin G, Herman A, Brice A, Durr A: Clinical and MRI findings in spinocerebellar ataxia 5. Neurology (in press).

111 Bürk K, Abele M, Fetter M et al: Autosomal dominant cerebellar ataxia typel: clinical features and MRI in families with SCA1, SCA2 and SCA3. Brain 1996; 119: 1497-1505.

112 Rivaud-Pechoux S, Dürr A, Gaymard B et al: Eye movement abnormalities correlate with genotype in autosomal dominant cerebellar ataxia typel. Ann Neurol 1998; 43: 297-302.

113 Gomez CM, Thompson RM, Gammack JT et al: Spinocerebellar ataxia type6: gaze-evoked and vertical nystagmus, Purkinje cell degeneration, and variable age of onset. Ann Neurol 1997; 42: 933-950.

114 Watanabe H, Tanaka F, M atsumoto $M$ et al: Frequency analysis of autosomal dominant cerebellar ataxis in Japanese patients and clinical characterization of spinocerebellar ataxia type6. Clin Genet 1998; 53: 13-19.

115 Robitaille Y, Lopes-Cendes I, Becher M, Rouleau G, Clark AW: The neuropathology of CAG repeat diseases: review and update of genetic and molecular features. Brain Pathol 1997; 7: 901-926. 
116 Gilman S, Sima AA, Junck L et al: Spinocerebellar ataxia type 1 with multiple system degeneration and glial cytoplasmic inclusions. Ann Neurol 1996; 39: 241-255.

117 Dürr A, Smadja D, Cancel G et al: Autosomal dominant cerebellar ataxia typel in Martinique (French West Indies): clinical and neuropathological analysis of 53 patients from three unrelated SCA2 families. Brain 1995; 118: 1573-1581.

118 Martin JJ, Van Regemorter N, Krols L et al: On an autosomal dominant form of retinal-cerebellar degeneration: an autopsy study of five patients in one family. Acta N europathol (Berl) 1994; 88: 277-286.

119 Kawakami H, Maruyama H, Nakamura Set al: Unique features of the CAG repeats in Machado-Joseph disease. Nat Genet 1995; 9: 344-345.

120 Dürr A, Stevanin G, Cancel G et al: Gender equality in MachadoJoseph disease. Nat Genet 1995; 11: 118-118.

121 Destefano AL, Farrer LA, Maciel $P$ et al: Gender equality in Machado-Joseph disease. Nat Genet 1995; 11: 118-119.

122 DeStefano AL, Cupples LA, Maciel P et al: A familial factor independent of CAG repeat length influences age at onset of Machado-Joseph disease. Am J Hum Genet 1996; 59: 119-127.

123 Lerer I, Merims D, Abeliovich D, Zlotogora J, Gadoth N: Machado-Joseph disease: correlation between the clinical features, the CAG repeat length and homozygosity for the mutation. Eur J Hum Genet 1996; 4: 3-7.

124 Sobue G, Doyu M, Nakao N et al: Homozygosity for MachadoJoseph disease gene enhances phenotypic severity [letter]. J Neurol Neurosurg Psychiatr 1996; 60: 354-356.

125 Geschwind DH, Perlman S, Figueroa KP, Karrim J, Baloh RW, Pulst SM: Spinocerebellar ataxia type6. Frequency of the mutation and genotype-phenotype correlations. Neurology 1997; 49: 1247-1251.

126 Matsumura R, Futamura N, Fujimoto $Y$ et al: Spinocerebellar ataxia type6. Molecular and clinical features of 35Japanese patients including one homozygous for the CAG repeat expansion. Neurology 1997; 49: 1238-1243.

127 Myers RH, Leavitt J, Farrer LA et al: Homozygote for Huntington disease. Am J Hum Genet 1989; 45: 615-618.

128 Dürr A, Hahn-Barma V, Brice A, Pecheux C, Dode C, Feingold J: Homozygosity in Huntington's disease. J Med Genet 1999; 36: 172-173.

129 Dürr A, Chneiweiss H, Khati $\mathrm{C}$ et al: Phenotypic variability in autosomal dominant cerebellar ataxia typel is unrelated to genetic heterogeneity. Brain 1993; 116: 1497-1508.

130 Jodice $C$, Malaspina $P$, Persichetti $F$ et al: Effect of trinucleotide repeat length and parental sex on phenotypic variation in spinocerebellar ataxial. Am J Hum Genet 1994; 54: 959-965.

131 Klockgether T, Kramer B, Ludtke R, Schols L, Laccone F: Repeat length and disease progression in spinocerebellar ataxia type3. Lancet 1996; 348: 830-830.

132 Tuite PJ, Rogaeva EA, St George-Hyslop PH, Lang AE: Doparesponsive parkinsonism phenotype of Machado-Joseph disease: confirmation of 14q CAG expansion. Ann Neurol 1995; 38: 684-687.

133 Burright EN, Clark HB, Servadio A et al: SCA1 transgenic mice: a model for neurodegeneration caused by an expanded CAG trinucleotide repeat. Cell 1995; 82: 937-948.

134 Ikeda H, Yamaguchi M, Sugai S, Aze Y, Narumiya S, Kakizuka A: Expanded polyglutamine in the Machado-Joseph disease protein induces cell death in vitro and in vivo. Nat Genet 1996; 13: 196-202.

135 Trottier Y, Lutz Y, Stevanin G et al: Polyglutamine expansion as a pathological epitope in Huntington's disease and four dominant cerebellar ataxias. Nature 1995; 378: 403-406.

136 Davies SW, Turmaine M, Cozens BA et al: Formation of neuronal intranuclear inclusions (NII) underlies the neurological dysfunction in mice transgenic for the HD mutation. Cell 1997; 90: 537-548

137 Lunkes A, Mandel J-L: Polyglutamines, nuclear inclusions and neurodegeneration. Nat Med 1997; 3: 1201-1202.
138 Ishikawa K, Fujigasaki H, Saegusa H et al: Abundant expression and cytoplasmic aggregations of [alpha]1A voltage-dependent calcium channel protein associated with neurodegeneration in spinocerebellar ataxia type6. Hum Mol Genet 1999; 8: 1185-1193.

139 Green H: Human genetic diseases due to codon reiteration: relationship to an evolutionary mechanism. Cell 1993; 74: 955-956.

140 Kahlem P, Terre C, Green H, Djian P: Peptides containing glutamine repeats as substrates for transglutaminase-catalyzed cross-linking: relevance to diseases of the nervous system. Proc Natl Acad Sci USA 1996; 93: 14580-14585.

141 Perutz MF, Johnson T, Suzuki M, Finch JT: Glutamine repeats as polar zippers: their possible role in inherited neurodegenerative diseases. Proc Natl Acad Sci USA 1994; 91: 5355-5358.

142 Kahlem P, Green H, Djian P: Transglutaminase action imitates Huntington's disease: selective polymerization of huntingtin containing expanded polyglutamine. Mol Cell 1998; 1: 595-601.

143 Igarashi S, Koide R, Shimohata T et al: Suppression of aggregate formation and apoptosis by transglutaminase inhibitors in cells expressing truncated DRPLA protein with an expanded polyglutamine stretch. Nat Genet 1998; 18: 111-117.

144 Saudou F, Finkbeiner S, Devys D, Greenberg ME: Huntingtin acts in the nucleus to induce apoptosis but death does not correlate with the formation of intranuclear inclusions. Cell 1998; 95: 55-66.

145 Becher MW, Kotzuk JA, Sharp AH et al: Intranuclear neuronal inclusions in Huntington's disease and dentatorubral and pallidoluysian atrophy: correlation between the density of inclusions and IT15 CAG triplet repeat length. Neurobiol Dis 1998; 4 387-397.

146 Warrick JM, Paulson HL, Gray-Board GL et al: Expanded polyglutamine protein forms nuclear inclusions and causes neural degeneration in Drosophila. Cell 1998; 93: 939-949.

147 Holmberg M, Duyckaerts C, Dürr A et al: Spinocerebellar ataxia type7 (SCA7): a neurodegenerative disorder with neuronal intranuclear inclusions. Hum Mol Genet 1998; 7: 913-918.

148 Sathasivam K, Hobbs C, Turmaine $M$ et al: Formation of polyglutamine inclusions in non-CNS tissue. Hum Mol Genet 1999; 8: 813-822.

149 Perutz MF: Glutamine repeats and neurodegenerative diseases: molecular aspects. Trends Biochem Sci 1999; 24: 58-63.

150 Klement IA, Skinner PJ, Kaytor MD et al: Ataxin-1 nuclear localization and aggregation: role in polyglutamine-induced disease in SCA1 transgenic mice. Cell 1998; 95: 41-53.

151 Hodgson JG, Agopyan N, Gutekunst CA et al: A YAC mouse model for Huntington's disease with full-length mutant huntingtin, cytoplasmic toxicity, and selective striatal neurodegeneration. Neuron 1999; 23: 181-192.

152 Sisodia SS: Nuclear inclusions in glutamine repeat disorders: are they pernicious, coincidental, or beneficial? Cell 1998; 95: 1-4.

153 Paulson HL, Perez MK, Trottier Y et al: Intranuclear inclusions of expanded polyglutamine protein in spinocerebellar ataxia type3. Neuron 1997; 19: 333-344.

154 Martindale D, Hackam A, Wieczorek A et al: Length of huntingtin and its polyglutamine tract influences localization and frequency of intracellular aggregates. Nat Genet 1998; 18: 150-154.

155 Merry DE, Kobayashi Y, Bailey CK, Taye AA, Fischbeck KH: Cleavage, aggregation and toxicity of the expanded androgen receptor in spinal and bulbar muscular atrophy. Hum Mol Genet 1998; 7: 693-701.

156 Ona VO, Li M, Vonsattel JP et al: Inhibition of caspase-1 slows disease progression in a mouse model of Huntington's disease. Nature 1999; 399: 263-267.

157 Difiglia M, Sapp E, Chase K et al: Huntingtin is a cytoplasmic protein associated with vesicles in human and rat brain neurons. Neuron 1995; 14: 1075-1081. 
158 Welch WJ, Gambetti P: Chaperoning brain diseases. Nature 1998; 392: 23-24.

159 Bailey CK, McCampbell A, Madura K, Merry DE: Biochemical analysis of high molecular weight protein aggregates containing expanded polyglutamine repeat androgen receptor. Am J Hum Genet 1998; 63 (Suppl): A8.

160 Cummings CJ, Mancini MA, Antalffy B, DeFranco DB, Orr HT, Zoghbi HY: Chaperone suppression of aggregation and altered subcellular proteasome localization imply protein misfolding in SCA1. Nat Genet 1998; 19: 148-154.

161 Paulson HL, Chai Y, Gray-Board G, Bonini N: Misfolding and aggregation in spinocerebellar ataxia 3: a role for cellular chaperones in glutamine-repeat disease. Am J Hum Genet 1998; 63 (Suppl): A8.

162 Perez MK, Paulson HL, Pendse SJ, Saionz SJ, Bonini NM, Pittman RN: Recruitment and the role of nuclear localization in polyglutaminemediated aggregation. J Cell Biol 1998; 143: 1457-1470.

163 Matilla A, Koshy BT, Cummings CJ, Isobe T, Orr HT, Zoghbi HY: The cerebellar leucinerich acidic nuclear protein interacts with ataxin-1. Nature 1997; 389: 974-978

164 Skinner PJ, Koshy BT, Cummings CJ et al: Ataxin-1 with an expanded glutamine tract alters nuclear matrix-associated structures. Nature 1997; 389: 971-974.

165 World Federation of Neurology Research Group on Huntington's Chorea, International Huntington Association: Guidelines for the molecular genetics predictive test in Huntington's disease. J Med Genet 1994; 31: 555-559.

166 Giunti P, Stevanin G, Worth P, David G, Brice A, Wood NW: Molecular and clinical study of 18 families with ADCA typell: evidence for genetic heterogeneity and de novo mutation. Am J Hum Genet 1999; 64: 1594-1603.

167 Komure O, Sano A, Nishino N et al: DNA analysis in hereditary dentatorubral-pallidoluysian atrophy: correlation between CAG repeat length and phenotypic variation and the molecular basis of anticipation. Neurology 1995; 45: 143-149.

168 Ikeuchi T, Koide R, Tanaka H et al: Dentatorubral-pallidoluysian atrophy: clinical features are closely related to unstable expansions of trinucleotide (CAG) repeat. Ann Neurol 1995; 37: 769-775.
169 La Spada AR, Roling DB, Harding AE et al: Meiotic stability and genotype-phenotype correlation of the trinucleotide repeat in X-linked spinal and bulbar muscular atrophy. Nat Genet 1992; 2: 301-304.

170 Biancalana V, Serville F, Pommier J, Julien J, Hanauer A, Mandel JL: Moderate instability of the trinucleotide repeat in spino bulbar muscular atrophy. Hum Mol Genet 1992; 1: 255-258.

171 Watanabe M, Abe K, Aoki M et al: Mitotic and meiotic stability of the CAG repeat in the X-linked spinal and bulbar muscular atrophy gene. Clin Genet 1996; 50: 133-137.

172 Duyao M, Ambrose C, Myers $R$ et al: Trinucleotide repeat length instability and age of onset in Huntington's disease. Nat Genet 1993; 4: 387-392.

173 Kremer B, Almqvist E, Theilmann J et al: Sex-dependent mechanisms for expansions and contractions of the CAG repeat on affected Huntington disease chromosomes. Am J Hum Genet 1995; 57: 343-350.

174 Dubourg O, Dürr A, Cancel G et al: Analysis of the SCA1 CAG repeat in a large number of families with dominant ataxia: clinical and molecular correlations. Ann Neurol 1995; 37: 176-180.

175 Stevanin G, Cassa E, Cancel G et al: Characterization of the unstable expanded CAG repeat in the MJD1 gene in four Brazilian families of Portuguese descent with Machado-Joseph disease. J Med Genet 1995; 32: 827-830.

176 Duyckaerts C, Dürr A, Cancel G, Brice A: Nuclear inclusions in spinocerebellar ataxia type1. Acta Neuropathol (Berl) 1999; 97: 201-207.

177 Koide R, Kobayashi S, Shimohata T et al: A neurological disease caused by an expanded CAG trinucleotide repeat in the TATAbinding protein gene: a new polyglutamine disease? Hum Mol Genet 1999; 8: 2047-2053.

178 Holmes SE, O'Hearn E, Mclnnis MG et al: Expansion of a novel CAG repeat in the $5^{\prime}$ region of gene encoding a subunit of protein phosphatase 2a is associated with spinocerebellar ataxia type 12 (SCA12). Am J Hum Genet 1999; 65 (Suppl): Abstract 14. 